\title{
Extended Fuzzy Analytic Hierarchy Process (E-FAHP): A General Approach
}

\author{
Javier Reig-Mullor ${ }^{1, *}$,, David Pla-Santamaria ${ }^{2}$ (I) and Ana Garcia-Bernabeu ${ }^{2}$ (]) \\ 1 Department Economics and Finance Studies, Universitas Miguel Hernandez, Avd. Universidad s/n, \\ 03202 Elche (Alicante), Spain \\ 2 Department of Economy and Social Science, Universitat Politècnica de València Alcoy Campus, \\ Plaza Ferrándiz y Carbonell, s/n, 03801 Alcoy (Alicante), Spain; dplansan@esp.upv.es (D.P.-S.); \\ angarber@esp.upv.es (A.G.-B.) \\ * Correspondence: javier.reig@umh.es
}

Received: 25 September 2020; Accepted: 9 November 2020; Published: 12 November 2020

\begin{abstract}
Fuzzy analytic hierarchy process (FAHP) methodologies have witnessed a growing development from the late 1980s until now, and countless FAHP based applications have been published in many fields including economics, finance, environment or engineering. In this context, the FAHP methodologies have been generally restricted to fuzzy numbers with linear type of membership functions (triangular numbers- $\mathrm{TN}$-and trapezoidal numbers- $\mathrm{TrN}$ ). This paper proposes an extended FAHP model (E-FAHP) where pairwise fuzzy comparison matrices are represented by a special type of fuzzy numbers referred to as $(m, n)$-trapezoidal numbers $(\operatorname{TrN}(m, n))$ with nonlinear membership functions. It is then demonstrated that there are a significant number of FAHP approaches that can be reduced to the proposed E-FAHP structure. A comparative analysis of E-FAHP and Mikhailov's model is illustrated with a case study showing that E-FAHP includes linear and nonlinear fuzzy numbers.
\end{abstract}

Keywords: AHP; fuzzy AHP; fuzzy numbers; (m,n)-trapezoidal numbers; MCDM

\section{Introduction}

One of the most frequently used MCDM tools which has been employed to solve intricate decision-making problems over the past years has been the analytic hierarchy process (AHP), proposed by Saaty [1]. The judgments made by the decision-makers rely on pairwise comparisons given by the relative weights of the criteria that appear in the intermediate steps of AHP. These judgments are based on information and knowledge on the problem provided by decision-makers (DMs). Therefore, the comparisons involve subjectivity in interpreting and assessing the problem, which means that the DMs standpoints have a profound effect on the final results [2].

There is widespread literature addressing the situation in which uncertainty stemming from imprecision and subjectivity in the evaluation process makes conventional AHP an inadequate tool. This is especially true in cases in which vagueness inherent in linguistic assessment [3]. This limitation, however, vanishes when fuzzy logic is included into the AHP methodology, which leads to Fuzzy Analytic Hierarchy Process (FAHP). In fact, a considerable number of research papers deal with the efficiency and applicability of FAHP, whether on its own or combined with different MCDM techniques. Such studies are closely related to fuzzy numbers having linear membership functions, that is to say, triangular number (TN) and in some cases, trapezoidal number $(\operatorname{TrN})$. By using fuzzy numbers with linear membership functions, complex nonlinear computations are avoided [4,5]. It should be noted that one of the main drawbacks when using linear membership functions lies with the problems related 
to finding a solution to a problem. These authors emphasize the importance of using a membership function which can be easily adjusted.

The purpose of this paper is to go one step further by proposing an extended framework which can provide insight into the presentation of FAHP approaches. In other words, the paper aims to provide a unifying basis for FAHP, starting from Mikhailov's fuzzy preference programming (FPP) method [6]. The basis of the FPP method is the fuzzy geometrical representations of the prioritization problem, which can be solved as a standard linear program with no difficulties. Some interesting properties of the method are worth mentioning, such as natural consistency index as well as good rank preservation and precision. Besides, it is regarded as a suitable alternative to other well-known prioritization methods, primarily when the decision-maker's preferences are highly inconsistent. The method we propose is called Extended FAHP (E-FAHP), which uses a special fuzzy number written as (m,n)-trapezoidal number $(\operatorname{TrN}(\mathrm{m}, \mathrm{n})$ [7], this number having a nonlinear membership function.

The proposed E-FAHP model can be extended to different types of nonlinear fuzzy numbers, which renders the model a practical tool to allow decision- makers to express their judgments.

In this sense, the integration of fuzzy numbers with linear or nonlinear membership functions into a unifying approach serves to clarify the close relationship between them. Moreover, the following theoretical and practical points seem to derive from this research:

1. From a theoretical point of view, all the valid results for E-FAHP using $(m, n)$-trapezoidal numbers are also valid for triangular numbers and it serves to derive priorities from a set of fuzzy judgments.

2. From a practical point of view, it seems helpful for practitioners to be aware that, regardless of the form adopted by fuzzy judgments (linear or nonlinear) they are formulating a particular case of the E-FAHP. In this way, an improved understanding of the linkages between both approaches is provided.

The paper is organized as follows. Section 2 reviews the recent uses of FAHP methodologies and presents the foundation of Mikhailov's fuzzy preference programming (FPP) method and describes the E-FAHP methodology using $(\mathrm{m}, \mathrm{n})$-trapezoidal numbers. In Section 3, we develop an illustrative example based on Mikhailov and Tsvetinov [8] case study. Finally, the conclusion of the paper appears in Section 4.

\section{Materials and Methods}

\subsection{Background and Literature Review}

Analytic hierarchy process (AHP) is a commonly used MCDM technique originally proposed by Saaty [1]. However, it has been subject to criticism since it employs an unbalanced scale of judgments and it is unable to handle imprecision and uncertainty in the pairwise comparison process [9]. In order to address these shortcomings, FAHP was developed to solve the hierarchical problems arising from the fact that decision-makers usually find that giving interval judgments is more accurate than giving fixed value judgments. As a result, FAHP uses both, fuzzy set theory and fuzzy numbers in order to express the uncertain comparison of opinions and it enables the incorporation of the incomplete, unquantifiable and non-obtainable information into the decision-making process.

Several authors have proposed fuzzy analytic hierarchy process (FAHP) applications [6,10-14], since it represents a systematic approach to the selection of alternatives and the resolution of problems by applying fuzzy set theory, which helps to express the uncertain comparison of opinions through the use of fuzzy numbers and AHP. The methods employed by van Laarhoven and Pedrcyz [10], Buckley [11], Enea and Piazza [13] and Krejčí et al. [14] derive fuzzy priorities represented as fuzzy numbers or fuzzy sets. On the other hand, Chang [12] and Mikhailov [6] obtain crisp priorities from fuzzy comparisons.

FAHP is frequently applied along with other tools, namely, goal programming (GP), fuzzy linear programming (FLP), fuzzy DEMATEL (FD), MOORA and fuzzy MOORA (FMOORA), TOPSIS and 
fuzzy TOPSIS (FTOPSIS), VIKOR, strengths, weaknesses, opportunities, threats (SWOT) analysis, grey relational analysis (GRA), fuzzy comprehensive evaluation method (FCEM), particle swarm optimization (PSO) and DEA. In Table 1, we display some relevant FAHP applications in which fuzzy numbers with linear membership functions, that is, triangular numbers (TN) are the main membership function used, followed by trapezoidal number $(\operatorname{TrN})$.

Table 1. Fuzzy AHP application areas, methods and types of fuzzy numbers.

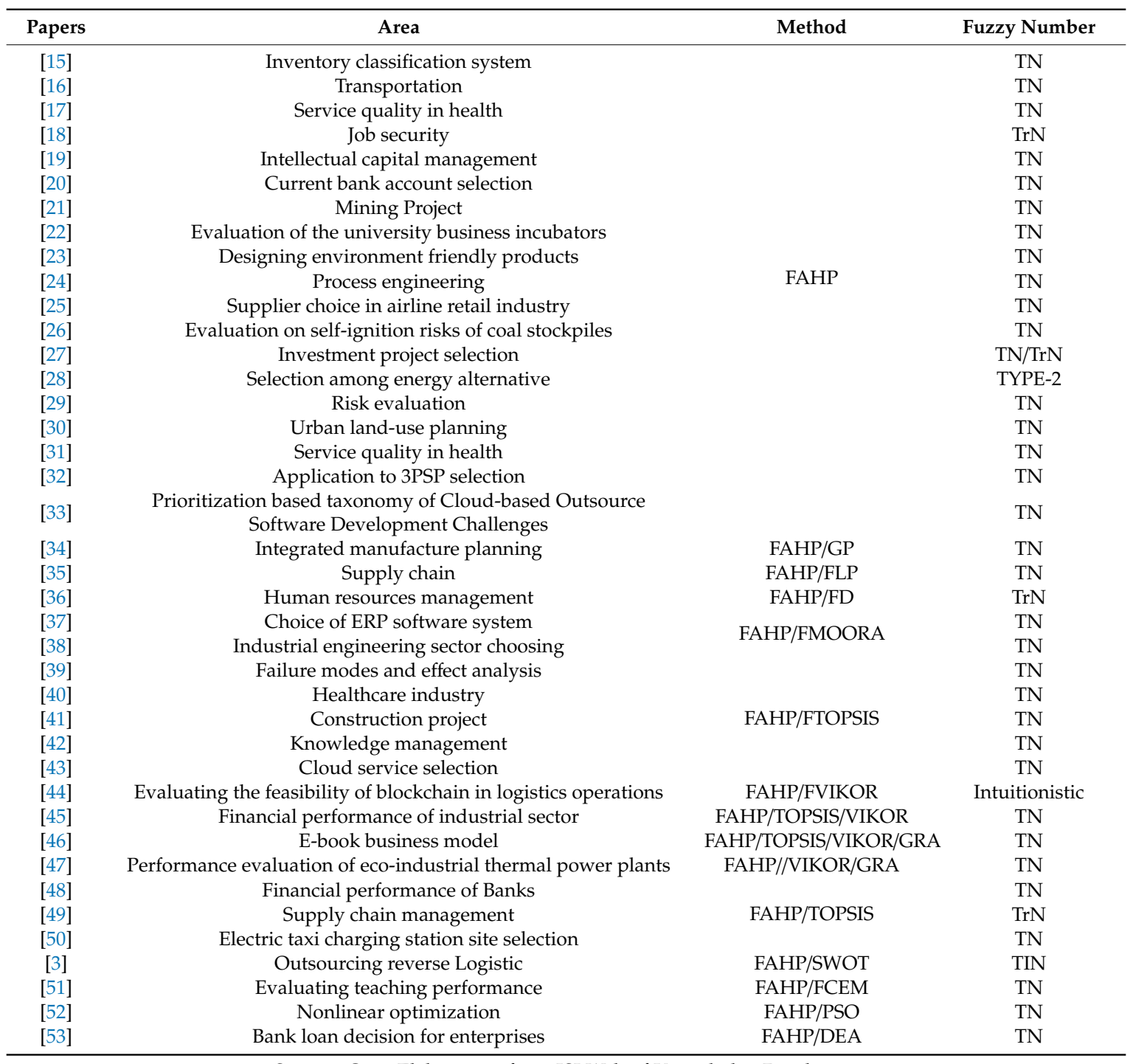

Source: Own Elaboration from ISI Web of Knowledge Database.

As Table 1 shows, a great number of contributions only apply FAHP. In other cases, however, when applying FAHP combined with other methodologies, a first step is to determine weights for each criterion using FAHP, while a second step entails establishing a ranking using some of the aforementioned methods. These techniques are primarily MCDM methodologies which complement FAHP and have been applied to many fields such as economics, finance, environment or engineering.

\subsection{Mikhailov's Model: Fuzzy Preference Programming (FPP)}

FAHP models operate basically using triangular or trapezoidal fuzzy numbers with linear membership functions, which involves the subsequent limitation for the decision-makers when their opinions must be represented.

The main steps in FAHP are the following: 
Just like in classical AHP, obtain a hierarchical structure from a decision-making problem.

The next step is to develop pairwise fuzzy comparison matrices. Take a prioritization problem with $n$ components, where fuzzy numbers denote pairwise fuzzy comparisons. As in classical AHP, every set of comparisons for each level needs $n(n-1) / 2$ judgments, these being used to build a positive fuzzy reciprocal comparison matrix $\widetilde{A}=\left\{\widetilde{a}_{i j}\right\}$ that:

$$
\left(\begin{array}{ccc}
\widetilde{a}_{11} & \cdots & \widetilde{a}_{1 t} \\
\vdots & \ddots & \vdots \\
\tilde{a}_{t 1} & \cdots & \tilde{a}_{t t}
\end{array}\right)
$$

Saaty [1] has set out a pairwise comparison scale ranging from 1 to 9 , where a value of 9 represents "extremely preferred", and a value of 1 is "equally preferred". Due to the complexity and uncertainty of many real-world decision-making problems, researchers acknowledge exact judgments are often unrealistic. When the information provided by the decision-makers is vague and imprecise, even more, when it is formulated in linguistic terms, FAHP becomes an appropriate tool. Therefore, different approaches of the fuzzy Saaty's fundamental scale emerge in the literature [19].

A fuzzy judgment matrix $\widetilde{A}=\left\{\widetilde{a}_{i j}\right\}$ that is constructed as in (1) where the components of the pairwise fuzzy comparison matrix are expressed by triangular numbers $T \widetilde{a}_{i j}=\left(a_{i j}^{1}, a_{i j}^{2}, a_{i j}^{3}\right)$, where $i, j=1, \ldots t$. Besides,

$$
\begin{gathered}
\text { If } i \neq j, a_{i j}^{1}<a_{i j}^{2}<a_{i j}^{3} \\
\text { If } i=j, \widetilde{a}_{i j}=\widetilde{a}_{j i}=(1,1,1) \\
\widetilde{a}_{i j} \simeq \frac{1}{\widetilde{a}_{j i}}
\end{gathered}
$$

Thus, when the proposed scale is $\widetilde{1}, \ldots, \widetilde{9}$, the fuzzy fundamental scale is known as a multiplicatively reciprocal pairwise comparison (multiplicative PCM).

In other cases, an alternative fuzzy scale is proposed for pairwise comparisons where fuzzy judgment matrix $\widetilde{A}=\left\{\widetilde{a}_{i j}\right\}$ is constructed as in (1) using elements from interval [0, 1], where 0.1 is "extremely not preferred" and 1 "extremely preferred". The components are expressed by triangular numbers $T \widetilde{a}_{i j}=\left(a_{i j^{\prime}}^{1} a_{i j}^{2}, a_{i j}^{3}\right)$, where $i, j=1, \ldots t$. Besides,

$$
\begin{gathered}
\text { If } i \neq j, a_{i j}^{1}<a_{i j}^{2}<a_{i j}^{3} \\
\text { If } i=j, \widetilde{a}_{i j}=\widetilde{a}_{j i}=(0.5,0.5,0.5) \\
\widetilde{a}_{i j}=1-\widetilde{a}_{j i}
\end{gathered}
$$

In this case, the scale is known as the Additive reciprocal pairwise comparison (Additive PCM). Multiplicative and additive PCM's are equivalent, and moreover a multiplicative PCM can be transformed to an additive PCM (see Krejči [54]). The substantial difference between the multiplicative PCM and the additive PCM are the scales decision-makers used [55]. In our proposal, we have opted for the multiplicative scale PCM as it is the most preferred by most researches [14], as well as by Mikhailov's model.

The vector of exact priorities is $w=\left(w_{1}, w_{2}, \ldots, w_{t}\right)^{T}$

The third step is control of coherence and resulting priorities, which evaluates consistency and also obtains priorities from the pairwise fuzzy matrices.

One last step is aggregation of priorities and classification of alternatives. By applying a simple weighted sum, we aggregate the local priorities computed in the distinct levels of the hierarchy of decisions. The global priorities thus obtained provide the final ranking and the selection of the best alternative. 
The reason why Mikhailov's methodology [56] has been selected is because it helps us evaluate consistency of the decision-makers" opinions by using the so-called $\lambda$ or "index of consistency" [52]. According to this methodology, fuzzy preference programming (FPP) is proposed to obtain priorities from the fuzzy comparison judgments, which removes some of the drawbacks of the fuzzy prioritization methods currently employed. This proposed approach does not involve the building up of complete fuzzy comparison matrices, and besides it allows us to derive priorities from an incomplete set of fuzzy judgments. Moreover, the approach remains invariant to the precise shape of the fuzzy sets that have been employed in the representation of judgments [52].

By employing $\alpha$-cuts, initial fuzzy judgments are converted into a series of interval judgments. The method is used to transform the FPP priority allocation problem into a fuzzy program. This allows us to derive clear priorities from interval judgments, which correspond to each $\alpha$-level cut. Therefore, the need for another fuzzy classification procedure disappears.

The FPP priority allocation problem consists in solving the following program [6]:

$$
\begin{aligned}
& \text { Maximize } \lambda \\
& \text { Subject to } \\
& \left(a_{i j}^{2}-a_{i j}^{1}\right) \lambda w_{j}-w_{i}+a_{i j}^{1} w_{j} \leq 0 \\
& \left(a_{i j}^{3}-a_{i j}^{2}\right) \lambda w_{j}+w_{i}-a_{i j}^{3} w_{j} \leq 0 \\
& \sum_{k=1}^{t} w_{k}=1 ; w_{k}>0 ; k=1,2, \ldots, t \\
& i=1,2, \ldots, t-1 ; j=1,2,3, \ldots, t ; j>i
\end{aligned}
$$

Mikhailov denotes $\lambda^{*}$ as "consistency index", which is used to evaluate the satisfaction level of the optimal priority vector $w^{*}$. When $\lambda^{*}$ is positive, all the solution coefficients entirely satisfy fuzzy opinions. This means that the initial set of fuzzy judgments is significantly consistent. Conversely, a negative value of $\lambda^{*}$ shows that the fuzzy judgments are highly inconsistent, that is to say, we can employ the optimal value of $\lambda^{*}$ as a consistency measure of the initial set of fuzzy judgments.

\subsection{Extended FAHP (E-FAHP) with $(m, n)$-Trapezoidal Numbers}

An extension of FAHP Mikhailov's model for its application with $(\mathrm{m}, \mathrm{n})$-trapezoidal numbers called Extended FHP (E-FAHP) is proposed. Before establishing the E-FAHP model, let us begin with a basic definition for $(\mathrm{m}, \mathrm{n})$-trapezoidal number.

Definition 1. (m,n)-trapezoidal number. Let us now define a type of fuzzy number called $(m, n)$-trapezoidal number, $\operatorname{Tr} \widetilde{A}_{(m, n)}=\left(a^{1}, a^{2}, a^{3}, a^{4}\right)_{(m, n)}$ where $a^{1} \leq a^{2} \leq a^{3} \leq a^{4} \in X$. Its membership function is provided by Appadoo [7]:

$$
\operatorname{Tr} \widetilde{A}_{(m, n)}(x)=\left\{\begin{array}{lr}
0, & x \leq a^{1} \\
1-\left(\frac{a^{2}-x}{a^{2}-a^{1}}\right)^{m}, & a^{1} \leq x \leq a^{2} \\
1, & a^{2} \leq x \leq a^{3} \\
1-\left(\frac{x-a^{3}}{a^{4}-a^{3}}\right)^{n}, & a^{3} \leq x \leq a^{4} \\
0, & x \geq a^{4}
\end{array}\right.
$$

The representation of $\operatorname{Tr} \widetilde{A}_{(m . n)}$, from the $\alpha$-cuts is:

$$
\operatorname{Tr} \widetilde{A}_{(m, n)}(\alpha)=\left[a_{L}(\alpha), a_{U}(\alpha)\right]=\left[a^{2}-\left(a^{2}-a^{1}\right)(1-\alpha)^{1 / m}, a^{3}+\left(a^{4}-a^{3}\right)(1-\alpha)^{1 / n}\right] \forall \alpha \in[0,1]
$$

From $\operatorname{Tr} \widetilde{A}_{(m, n)}$, we can obtain a trapezoidal number $(\operatorname{Tr} \widetilde{A})$, when $\mathrm{m}=\mathrm{n}=1$, that is:

$$
\operatorname{Tr} \widetilde{A}(\alpha)=\left[a_{L}(\alpha), a_{U}(\alpha)\right]=\left[a^{2}-\left(a^{2}-a^{1}\right)(1-\alpha), a^{3}+\left(a^{4}-a^{3}\right)(1-\alpha)\right] \forall \alpha \in[0,1]
$$


In a similar way we could obtain a triangular number $(T \widetilde{A})$, from $\operatorname{Tr} \widetilde{A}_{(m, n)}$, if $\mathrm{m}=\mathrm{n}=1$, and from $a^{2}=a^{3}$, and we rewrite $a^{3}$ for $a^{4}$, that is:

$$
T \widetilde{A}(\alpha)=\left[a_{L}(\alpha), a_{U}(\alpha)\right]=\left[a^{2}-\left(a^{2}-a^{1}\right)(1-\alpha), a^{2}+\left(a^{3}-a^{2}\right)(1-\alpha)\right] \forall \alpha \in[0,1]
$$

The membership function of $\operatorname{Tr} \widetilde{A}_{(m, n)}$ where $\mathrm{m}, \mathrm{n} \in[0, \infty]$, is displayed in Figure 1:

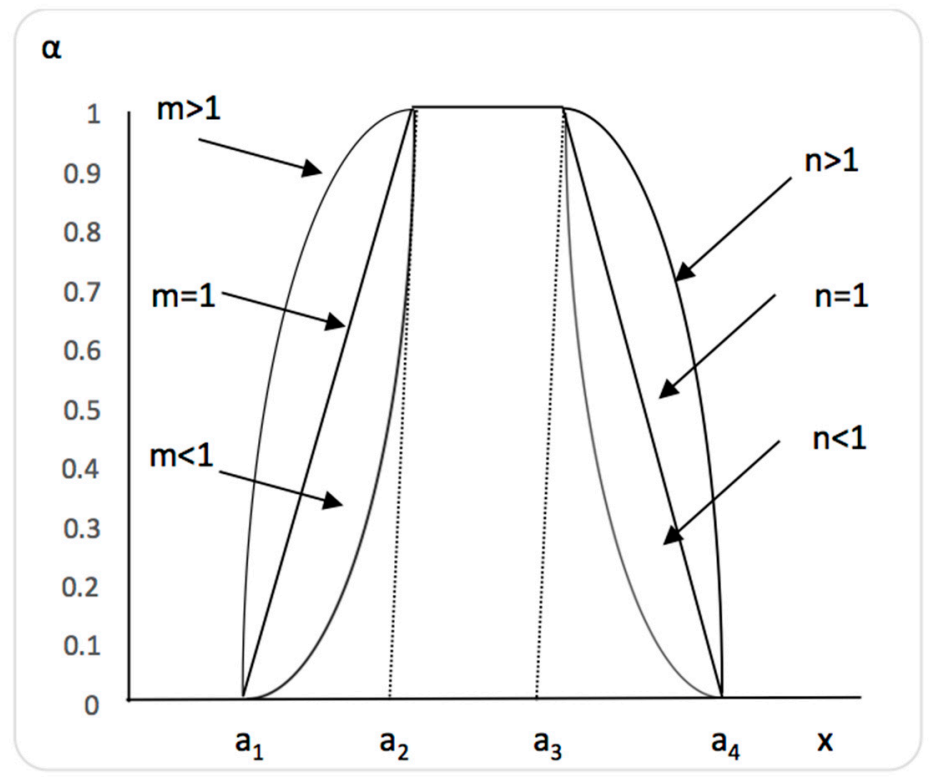

Figure 1. Membership function of $\operatorname{Tr} \widetilde{A}_{(m, n)}$.

Figure 1 depicts different types of graphic representations for the $\operatorname{Tr} \widetilde{A}_{(m, n)}$, which is symmetric when $a^{2}-a^{1}=a^{4}-a^{3}$ and $\mathrm{m}=\mathrm{n}$, and asymmetric when $a^{2}-a^{1} \neq a^{4}-a^{3}$ or $\mathrm{m} \neq \mathrm{n}$ or both. On the other hand, when $\mathrm{m}=\mathrm{n}=1$ and $a^{2} \neq a^{3}$ we have the representation of the trapezoidal number $(\operatorname{Tr} \widetilde{A})$, while if $\mathrm{m}=\mathrm{n}=1$ and $a^{2}=a^{3}$ we can derive the triangular number $(T \widetilde{A})$.

Next, we state the main operations (see Appadoo [57]), with $\operatorname{Tr} \widetilde{A}_{(m a, n a)}$ and $\operatorname{Tr} \widetilde{B}_{(m b, n b)}$ being two $(\mathrm{m}, \mathrm{n})$-trapezoidal numbers,

$$
\begin{aligned}
& \operatorname{Tr} \widetilde{A}_{(m a, n a)}(\alpha)=\left[a_{L}(\alpha), a_{U}(\alpha)\right]=\left[a^{2}-\left(a^{2}-a^{1}\right)(1-\alpha)^{1 / m a}, a^{3}+\left(a^{4}-a^{3}\right)(1-\alpha)^{1 / n a}\right] \forall \alpha \in[0,1] \\
& \operatorname{Tr} \widetilde{B}_{(m b, n b)}(\alpha)=\left[b_{L}(\alpha), b_{U}(\alpha)\right]=\left[b^{2}-\left(b^{2}-b^{1}\right)(1-\alpha)^{1 / m b}, b^{3}+\left(b^{4}-b^{3}\right)(1-\alpha)^{1 / n b}\right] \forall \alpha \in[0,1]
\end{aligned}
$$

The aggregation of $\operatorname{Tr} \widetilde{A}_{(m a, n a)}$ and $\operatorname{Tr} \widetilde{B}_{(m b, n b)}$, will be given by:

$\operatorname{Tr} \widetilde{A}_{(m a, n a)}(\alpha)+\operatorname{Tr} \widetilde{B}_{(m b, n b)}(\alpha)=\left[a_{L}(\alpha)+b_{L}(\alpha), a_{U}(\alpha)+b_{U}(\alpha)\right]=$ $=\left[\left(a^{2}-\left(a^{2}-a^{1}\right)(1-\alpha)^{1 / m a}\right)+\left(b^{2}-\left(b^{2}-b^{1}\right)(1-\alpha)^{1 / m b}\right),\left(a^{3}+\left(a^{4}-a^{3}\right)(1-\alpha)^{1 / n a}\right)+\left(b^{3}+\left(b^{4}-b^{3}\right)(1-\alpha)^{1 / n b}\right)\right]$ $\forall \alpha \in[0,1]$

The difference between $\operatorname{Tr} \widetilde{A}_{(m a, n a)}$ and $\operatorname{Tr} \widetilde{B}_{(m b, n b)}$, will be given by:

$$
\begin{aligned}
& \operatorname{Tr} \widetilde{A}_{(m a, n a)}(\alpha)-\operatorname{Tr} \widetilde{B}_{(m b, n b)}(\alpha)=\left[a_{L}(\alpha)-b_{U}(\alpha), a_{U}(\alpha)-b_{L}(\alpha)\right]= \\
& =\left[\left(a^{2}-\left(a^{2}-a^{1}\right)(1-\alpha)^{1 / m a}\right)-\left(b^{3}+\left(b^{4}-b^{3}\right)(1-\alpha)^{1 / m b}\right),\left(a^{3}+\left(a^{4}-a^{3}\right)(1-\alpha)^{1 / n a}\right)-\left(b^{2}-\left(b^{2}-b^{1}\right)(1-\alpha)^{1 / n b}\right)\right] \\
& \forall \alpha \in[0,1]
\end{aligned}
$$


The multiplication of $\operatorname{Tr} \widetilde{A}_{(m a, n a)}$ and $\operatorname{Tr} \widetilde{B}_{(m b, n b)}$, will be given by:

$$
\begin{aligned}
& \operatorname{Tr} \widetilde{A}_{(m a, n a)}(\alpha) \times \operatorname{Tr} \widetilde{B}_{(m b, b)}(\alpha)=\left[a_{L}(\alpha) \times b_{L}(\alpha), a_{U}(\alpha) \times b_{U}(\alpha)\right]= \\
& =\left[\left(a^{2}-\left(a^{2}-a^{1}\right)(1-\alpha)^{1 / m a}\right) \times\left(b^{2}-\left(b^{2}-b^{1}\right)(1-\alpha)^{1 / m b}\right),\left(a^{3}+\left(a^{4}-a^{3}\right)(1-\alpha)^{1 / n a}\right) \times\left(b^{3}+\left(b^{4}-b^{3}\right)(1-\alpha)^{1 / n b}\right)\right] \\
& \forall \alpha \in[0,1]
\end{aligned}
$$

The division between $\operatorname{Tr} \widetilde{A}_{(m a, n a)}$ and $\operatorname{Tr} \widetilde{B}_{(m b, n b)}$, will be given by:

$$
\frac{\operatorname{Tr} \widetilde{A}_{(m a, n a)}(\alpha)}{\operatorname{Tr} \widetilde{B}_{(m b, n b)}(\alpha)}=\left[\frac{a_{L}(\alpha)}{b_{U}(\alpha)}, \frac{a_{U}(\alpha)}{b_{L}(\alpha)}\right]=\left[\frac{\left(a^{2}-\left(a^{2}-a^{1}\right)(1-\alpha)^{1 / m a}\right)}{\left(b^{3}+\left(b^{4}-b^{3}\right)(1-\alpha)^{1 / n b}\right)}, \frac{\left(a^{3}+\left(a^{4}-a^{3}\right)(1-\alpha)^{1 / n a}\right)}{\left(b^{2}-\left(b^{2}-b^{1}\right)(1-\alpha)^{1 / m b}\right)}\right] \forall \alpha \in[0,1]
$$

In our case, and unlike Mikhailov's model, let us suppose a fuzzy judgment matrix $\widetilde{A}=\left\{\widetilde{a}_{i j}\right\}$, built as in (1). We represent the components of the pairwise fuzzy comparison matrix by $\operatorname{Tra}_{i j(m, n)}=\left(a_{i j^{\prime}}^{1} a_{i j^{\prime}}^{2} a_{i j^{3}}^{3}, a_{i j}^{4}\right)_{(m, n)}$, where $i, j=1, \ldots$. Also,

$$
\begin{gathered}
\text { If } i \neq j, a_{i j}^{1}<a_{i j}^{2}<a_{i j}^{3}<a_{i j}^{4} \\
\text { If } i=j, \widetilde{a}_{i j}=\widetilde{a}_{j i}=(1,1,1,1)_{(m, n)}
\end{gathered}
$$

As a result, an exact priority vector $w=\left(w_{1}, w_{2}, \ldots, w_{t}\right)^{T}$ which derives from $\widetilde{A}$ should satisfy fuzzy inequations:

$$
a_{i j}^{1} \leq \frac{w_{i}}{w_{j}} \widetilde{\leq} a_{i j}^{4}
$$

where $w_{i}>0, w_{j}>0, i \neq j$ and symbol $\widetilde{\leq}$ represent "fuzzy less than or equal to".

In order to measure the satisfaction degree of different crisp relationships $w_{i} / w_{j}$ as regards double side inequality in Equation (4), we can define a new membership function from (3):

$$
\mu_{i j}\left(\frac{w_{i}}{w_{j}}\right)=\left\{\begin{array}{lr}
0, & \left(\frac{w_{i}}{w_{j}}\right) \leq a_{i j}^{1} \\
1-\left(\frac{\left.a_{i j}^{2}-\left(\frac{w_{i}}{w_{j}}\right)\right)^{m}}{a_{i j}^{2}-a_{i j}^{1}}\right)^{m}, & a_{i j}^{1} \leq\left(\frac{w_{i}}{w_{j}}\right) \leq a_{i j}^{2} \\
1, & a_{i j}^{2} \leq\left(\frac{w_{i}}{w_{j}}\right) \leq a_{i j}^{3} \\
1-\left(\frac{\left(\frac{w_{i}}{w_{j}}\right)-a_{i j}^{3}}{a_{i j}^{4}-a_{i j}^{3}}\right)^{n}, & a_{i j}^{3} \leq\left(\frac{w_{i}}{w_{j}}\right) \leq a_{i j}^{4} \\
0, & \left(\frac{w_{i}}{w_{j}}\right) \geq a_{i j}^{4}
\end{array}\right.
$$

The solution to the prioritization problem through FPP relies on two main assumptions [56].

Assumption 1. This assumption requires the existence of non-empty fuzzy feasible area $\widetilde{P}$ on the $(n-1)$ -dimensional simplex $Q^{n-1}$

$$
Q^{n-1}=\left\{\left(w_{1}, w_{2}, \ldots, w_{t}\right)\left|w_{i}\right\rangle 0, \sum_{1}^{t} w_{i}=1\right\}
$$

Being defined as an intersection of the membership functions, similar to (5) and the simplex hyperplane (6), the membership function of the fuzzy feasible area $\widetilde{P}$ is given by:

$$
\mu_{P}(w)=\min _{i j}\left\{\mu_{i j}(w)|i=1, \ldots, t-1 ; j=2, \ldots, t ; j\rangle i\right\}
$$


Once membership functions (5) are defined as L-fuzzy sets, we can relax the assumption of non-emptiness of $\widetilde{P}$ on the simplex. If fuzzy judgments are significantly inconsistent, then $\mu_{P}(w)$ could take negative values for all normalized priority vectors $w \in Q^{n-1}$.

Assumption 2. The second assumption incorporates a selection rule determining a priority vector which has the maximum degree of membership in aggregate membership function (7). It can be easily proven that $\mu_{P}(w)$ is a convex set and therefore priority vector $w^{*} \in Q^{n-1}$ always has the highest degree of membership.

$$
\mu_{P}\left(w^{*}\right)=\max \min _{i j}\left\{\mu_{i j}(w) \mid w \in Q^{n-1}\right\}
$$

Let us represent the maximin of prioritization problem (8) as follows:

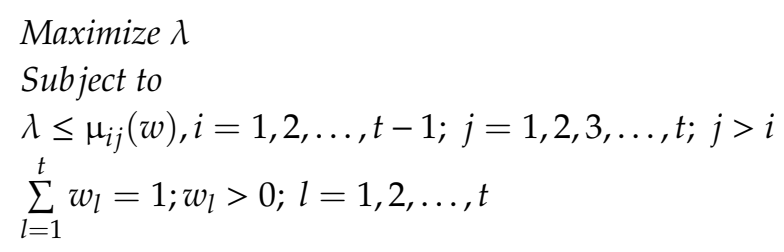

Taking into account the particular form of membership function (5), problem (9) can be converted into the E-FAHP preference programming:

$$
\begin{aligned}
& \text { Maximize } \lambda \\
& \text { Subject to } \\
& {\left[w_{j}\left(a_{i j}^{2}-a_{i j}^{1}\right)\right]^{m}(\lambda-1)+\left(a_{i j}^{2} w_{j}-w_{i}\right)^{m} \leq 0} \\
& {\left[w_{j}\left(a_{i j}^{4}-a_{i j}^{3}\right)\right]^{n}(\lambda-1)+\left(w_{i}-a_{i j}^{3} w_{j}\right)^{n} \leq 0} \\
& \sum_{k=1}^{t} w_{k}=1 ; i=1,2, \ldots, t-1 ; j=1,2,3, \ldots, t ; j>i ; w_{k}>0 ; k=1,2, \ldots, t
\end{aligned}
$$

If the elements of the pairwise fuzzy comparison matrix were represented by trapezoidal numbers $\operatorname{Tr} \widetilde{a}_{i j}=\left(a_{i j}^{1}, a_{i j}^{2}, a_{i j}^{3}, a_{i j}^{4}\right)$, where $i, j=1, \ldots t$, that is $\mathrm{m}=\mathrm{n}=1$, then the problem would become:

$$
\begin{aligned}
& \text { Maximize } \lambda \\
& \text { Subject to } \\
& \left(a_{i j}^{2}-a_{i j}^{1}\right) \lambda w_{j}-w_{i}+a_{i j}^{1} w_{j} \leq 0 \\
& \left(a_{i j}^{4}-a_{i j}^{3}\right) \lambda w_{j}+w_{i}-a_{i j}^{4} w_{j} \leq 0 \\
& \sum_{k=1}^{t} w_{k}=1 ; w_{k}>0 ; k=1,2, \ldots, t \\
& i=1,2, \ldots, t-1 ; j=1,2,3, \ldots, t ; j>i
\end{aligned}
$$

\section{Results}

In this section, we will illustrate our approach by solving a practical case of FAHP problem given in Mikhailov and Tsvetinov [8] with the help of E-FAHP. The problem is to assess three potential service providers considering three main criteria, namely, Pricing, Service, Quality and Delivery Time. Additionally, each main criterion is divided into two subcriteria, which are Cost-based and Demand-based Pricing, Reliable and Responsive Service Quality and Immediate and Negotiable Delivery Time, as Figure 2 shows: 


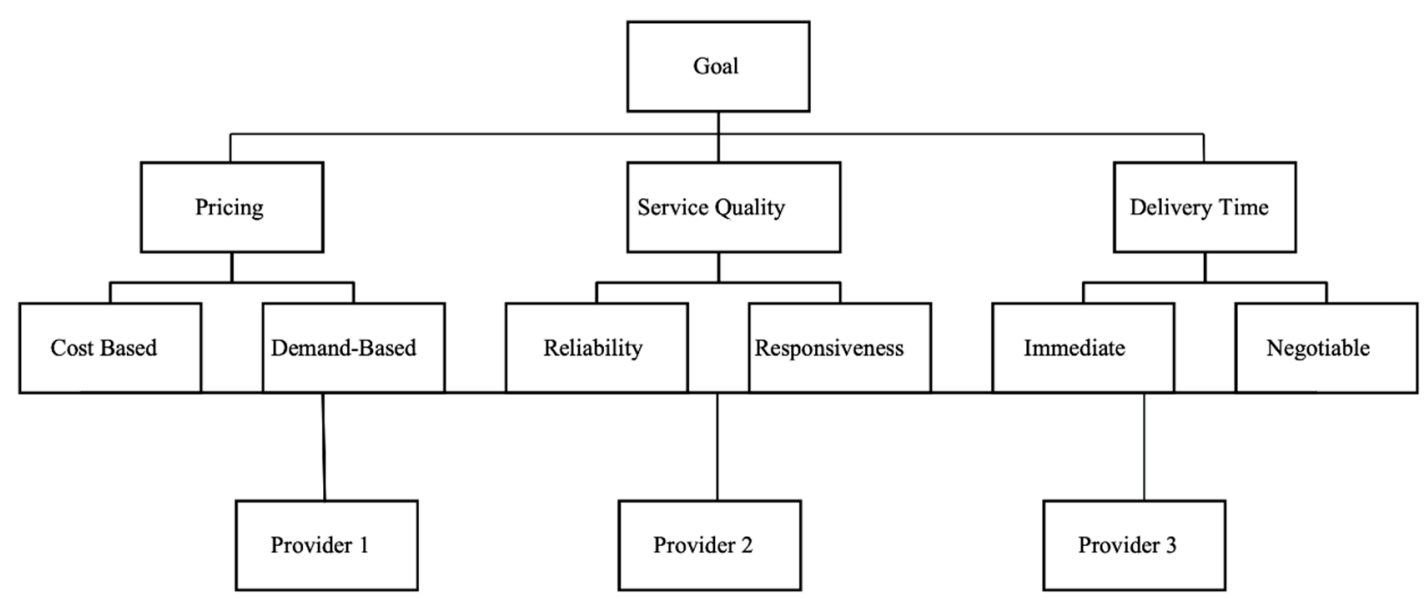

Figure 2. Decision Hierarchy [8].

The aim is to choose a service provider which satisfies all criteria in an optimal way. Table 2 displays the fuzzy pairwise comparison judgments of the main criteria.

Table 2. Mikhailov and Tsvetinov [8] pairwise comparison matrix.

\begin{tabular}{cccc}
\hline Goal & Pricing & Service Quality & Delivery Time \\
\hline Pricing & 1 & $(2,3,4)$ & $(1,2,3)$ \\
Service Quality & $\frac{1}{(2,3,4)}$ & 1 & $\left(\frac{1}{3}, \frac{1}{2}, 1\right)$ \\
Delivery Time & $\frac{1}{(1,2,3)}$ & $\frac{1}{\left(\frac{1}{3}, \frac{1}{2}, 1\right)}$ & 1 \\
\hline
\end{tabular}

By applying Mikhailov's model (2), the corresponding criteria weights yield:

$$
\begin{gathered}
w_{1}(\text { Pricing })=0.538 \\
w_{2}(\text { ServiceQuality })=0.170 \\
w_{3}(\text { DeliveryTime })=0.292 \\
\lambda=0.838
\end{gathered}
$$

To apply E-FAHP model (10), first we express the triangular numbers (TN) as $(\mathrm{m}, \mathrm{n})$-trapezoidal numbers.

$$
\operatorname{Tr} \widetilde{a}_{i j(m, n)}=\left(a_{i j}^{1}, a_{i j}^{2}, a_{i j}^{3}, a_{i j}^{4}\right)_{(m, n)}
$$

That is: $a_{i j}^{2}=a_{i j}^{3}$ and $m=n=1$.

In Table 3, the corresponding trapezoidal numbers when $m=n=1$ and $a_{i j}^{2}=a_{i j}^{3}$ are specified.

Table 3. Fuzzy pairwise comparison matrix using $\operatorname{Tr} \widetilde{a}_{i j(m, n)}$ when $m=n=1$ and $a_{i j}^{2}=a_{i j}^{3}$.

\begin{tabular}{cccc}
\hline Goal & Pricing & Service Quality & Delivery Time \\
\hline Pricing & 1 & $(2,3,3,4)_{(1,1)}$ & $(1,2,2,3)_{(1,1)}$ \\
Service Quality & $\frac{1}{(2,3,3,4)_{(1,1)}}$ & 1 & $\left(\frac{1}{3}, \frac{1}{2}, \frac{1}{2}, 1\right)_{(1,1)}$ \\
Delivery Time & $\frac{1}{(1,2,2,3)_{(1,1)}}$ & $\frac{1}{\left(\frac{1}{3}, \frac{1}{2}, \frac{1}{2}, 1\right)_{(1,1)}}$ & 1 \\
\hline
\end{tabular}


To obtain the weights for each criterion, we apply E-FAHP model (10). In this case, we can check that weights of the main criteria correspond with the results obtained by Mikhailov and Tsvetinov [8].

$$
\begin{gathered}
w_{1}(\text { Pricing })=0.538 \\
w_{2}(\text { ServiceQuality })=0.170 \\
w_{3}(\text { DeliveryTime })=0.292 \\
\lambda=0.838
\end{gathered}
$$

Next, we propose the same case study with different $a_{i j}^{2}<a_{i j}^{3}$ and $m=n=1$. That is a trapezoidal number:

$$
\operatorname{Tr} \widetilde{a}_{i j}=\operatorname{Tr} \widetilde{a}_{i j(1,1)}=\left(a_{i j}^{1}, a_{i j}^{2}, a_{i j}^{3}, a_{i j}^{4}\right)_{(1,1)}
$$

With the fuzzy pairwise comparison matrix shown in Table 4.

Table 4. Fuzzy pairwise comparison matrix using $\operatorname{Tr} \widetilde{a}_{i j(m, n)}$ when $a_{i j}^{2}<a_{i j}^{3}$ and $m=n=1$.

\begin{tabular}{cccc}
\hline Goal & Pricing & Service Quality & Delivery Time \\
\hline Pricing & 1 & $(1,2,3,4)_{(1,1)}$ & $\left(1, \frac{3}{2}, 2,3\right)_{(1,1)}$ \\
Service Quality & $\frac{1}{(1,2,3,4)_{(1,1)}}$ & 1 & $\left(\frac{1}{5}, \frac{1}{3}, \frac{1}{2}, 1\right)_{(1,1)}$ \\
Delivery Time & $\frac{1}{\left(1, \frac{3}{2}, 2,3\right)_{(1,1)}}$ & $\frac{1}{\left(\frac{1}{5}, \frac{1}{3}, \frac{1}{2}, 1\right)_{(1,1)}}$ & 1 \\
\hline
\end{tabular}

To obtain the weights for each criterion, we apply E-FAHP model (10) or (11) developed in this paper:

$$
\begin{gathered}
w_{1}(\text { Pricing })=0.500 \\
w_{2}(\text { ServiceQuality })=0.167 \\
w_{3}(\text { DeliveryTime })=0.333 \\
\lambda=1
\end{gathered}
$$

To conclude, the following case study is presented:

$\operatorname{Tr} \widetilde{a}_{i j(m, n)}=\left(a_{i j^{\prime}}^{1} a_{i j^{\prime}}^{2} a_{i j^{\prime}}^{3} a_{i j}^{4}\right)_{(m, n)}$, where, $a_{i j}^{2}<a_{i j}^{3}$ and $m \neq n$. See data in Table 5 .

Table 5. Fuzzy pairwise comparison matrix using $\operatorname{Tra}_{i j(m, n)}$ when $\mathrm{m} \neq \mathrm{n}$ and $a_{i j}^{2}<a_{i j}^{3}$.

\begin{tabular}{cccc}
\hline Goal & Pricing & Service Quality & Delivery Time \\
\hline Pricing & 1 & $(1,2,3,4)_{(6,5)}$ & $\left(1, \frac{3}{2}, 2,3\right)_{(3,2)}$ \\
Service Quality & $\frac{1}{(1,2,3,4)_{(6,5)}}$ & 1 & $\left(\frac{1}{5}, \frac{1}{3}, \frac{1}{2}, 1\right)_{(4,7)}$ \\
Delivery Time & $\frac{1}{\left(1, \frac{3}{2}, 2,3\right)_{(3,2)}}$ & $\frac{1}{\left(\frac{1}{5}, \frac{1}{3}, \frac{1}{2}, 1\right)_{(4,7)}}$ & 1 \\
\hline
\end{tabular}

To obtain the weights for each criterion, we apply the proposed E-FAHP model (10):

$$
\begin{gathered}
w_{1}(\text { Pricing })=0.471 \\
w_{2}(\text { Service Quality })=0.163 \\
w_{3}(\text { DeliveryTime })=0.366 \\
\lambda=0.493
\end{gathered}
$$


In Table 6, we summarize the values of weights and consistency index according to the type of $(\mathrm{m}, \mathrm{n})$-trapezoidal number used to represent the pairwise comparison in the Mikhailov and Tsvetinov [8] (first column) and in the proposed E-FAHP (columns 2-4). As can be noted, the values of weights $\left(w^{*}\right)$ and the consistency index $\lambda^{*}$ obtained by applying model (2) where the pairwise comparison are expressed by using triangular numbers $\left(T_{a_{i j}}\right)$ coincide with the values of the E-FAHP model when the corresponding $(\mathrm{m}, \mathrm{n})$-trapezoidal number $\left(\operatorname{Tr} \widetilde{a}_{i j}\right)$ is chosen as a particular case of a triangular number (see Table 3).

Table 6. Results from Mikhailov and Tsvetinov and E-FAHP model.

\begin{tabular}{|c|c|c|c|c|}
\hline & FAHP & \multicolumn{3}{|c|}{ E-FAHP } \\
\hline & $\begin{array}{l}\text { Mikhailov and Tsvetinov } \\
\qquad\left(\tilde{T}_{i j}\right)\end{array}$ & $\begin{array}{c}m=n=1 \text { and } a_{i j}^{2}=a_{i j}^{3} \\
\left(T \tilde{a}_{i j}\right)\end{array}$ & $\begin{array}{c}m=n=1 \text { and } a_{i j}^{2}<a_{i j}^{3} \\
\left(\operatorname{Tr} \tilde{a}_{i j}\right)\end{array}$ & $\begin{array}{c}m \neq n \text { and } a_{i j}^{2}<a_{i j}^{3} \\
\left(\operatorname{Tr} \tilde{a}_{i j(m, n)}\right)\end{array}$ \\
\hline$w_{1}$ & 0.538 & 0.538 & 0.500 & 0.471 \\
\hline$w_{2}$ & 0.170 & 0.170 & 0.167 & 0.163 \\
\hline$w_{3}$ & 0.292 & 0.292 & 0.333 & 0.366 \\
\hline$\lambda$ & 0.838 & 0.838 & 1 & 0.493 \\
\hline
\end{tabular}

With the aim of illustrating the potential use and applicability of the proposed E-FAHP, we extend the use of the Mikhailov and Tsvetinov [8], in which the pairwise comparison only can be represented by means of triangular numbers $\left(T \widetilde{a}_{i j}\right)$, to other types of fuzzy numbers. In particular, we derive the weights $\left(w^{*}\right)$ for the special cases in which the pairwise comparisons are expressed by $(\mathrm{m}, \mathrm{n})$-trapezoidal number $\left(\operatorname{Tr} \widetilde{a}_{i j(m, n)}\right)$ from Table 4 and from Table 5. It can be observed that the values of weights obtained for this case study are similar but not strictly identical. In addittion, in Table 6, bottom row, the value of the consistency index $\lambda$ for each optimal solution is displayed. From this row we can see that the fuzzy judgments when $\mathrm{m}=\mathrm{n}=1$ and $a_{i j}^{2}<a_{i j}^{3}\left(\operatorname{Tra}_{i j}\right)$ are the most consistent $\lambda=1$. Then, the solution ratio $w_{\mathrm{i}} / w_{\mathrm{j}}$ for all scores coincides with the highest level of the membership functions of the fuzzy comparison judgments as shown in Table 6, that is, $\left(w_{1} / w_{2}\right)=(0.500 / 0.167)=3$, $\left(w_{1} / w_{3}\right)=(0.500 / 0333)=1.5$ and $\left(w_{2} / w_{3}\right)=(0.167 / 0.333)=0.5$.

Clearly, the lower the vagueness and uncertainty of the decision-maker judgments, the higher the accuracy of the model. However, while the Mikhailov's model is only applicable for triangular numbers $\left(T \widetilde{T}_{i j}\right)$, the proposed E-FAHP model affords the possibility of using it in a broad range of fuzzy numbers.

\section{Conclusions}

The general approach E-FAHP proposed in this paper is regarded as tentative for the following reasons. Firstly, the fuzzy prioritization method herein proposed enables us to obtain clear priorities based on a nonlinear optimization model for consistent and inconsistent pairwise judgments. In this way priority fuzzy computations and fuzzy classification techniques can be avoided. And secondly, in the proposed nonlinear optimization method, pairwise opinions are expressed as $(m, n)$-trapezoidal numbers. This is an appropriate formulation for priority allocation problems in which opinions are expressed as fuzzy numbers, regardless of the form adopted by fuzzy judgments (linear or nonlinear). Additionally, this formulation allows one to perform prioritization problem resolution in which judgments are represented by different types of fuzzy numbers (linear and nonlinear) or crisp numbers.

Despite the fact that FAHP technique is a well-known MCDM methodology, its integration into a unifying approach for both linear and nonlinear fuzzy numbers help clarify the close relationship between them. In the illustrative example, it is then demonstrated that different FAHP approaches can be reduced to the E-FAHP structure when the pairwise judgments are represented by $(\mathrm{m}, \mathrm{n})$-trapezoidal numbers.

Practitioners should be aware that, whatever the FAHP model they are building, they are actually formulating a particular case of E-FAHP. Therefore, E-FAHP can be seen as a general 
framework that can lead to a better understanding and presentation of the different FAHP approaches. Accordingly, the proposed E-FAHP can be a powerful tool for analyzing multicriteria decision-making problems with imprecise preference judgments in a wide spectrum of fields such as logistics, finance or sustainability to name but a few. Moreover, it can be used both individually or combined with other methods as for example VIKOR, TOPSIS, GRA, SWOT or MOORA.

In the future we plan to investigate if and how we can formulate an extended version of the fuzzy analytic network process as well as to develop applications to combine the E-FAHP model with other models in order to get rankings or fuzzy rankings.

Author Contributions: J.R.-M. conceived and designed the methodology; D.P.-S. and A.G.-B. contributed to the literature review; A.G.-B. made proofreading and supervision. All authors have read and agreed to the published version of the manuscript.

Funding: This research received no external funding.

Conflicts of Interest: The authors declare no conflict of interest.

\section{References}

1. Saaty, T.L. The Analytic Hierarchy Process; McGraw-Hill Inc.: New York, NY, USA, 1980; ISBN 0070543712.

2. Chai, J.; Liu, J.N.K.; Ngai, E.W.T. Application of decision-making techniques in supplier selection: A systematic review of literature. Expert Syst. Appl. 2013, 40, 3872-3885. [CrossRef]

3. Tavana, M.; Zareinejad, M.; Di Caprio, D.; Kaviani, M.A. An integrated intuitionistic fuzzy AHP and SWOT method for outsourcing reverse logistics. Appl. Soft Comput. J. 2016, 40, 544-557. [CrossRef]

4. Medasani, S.; Kim, J.; Krishnapuram, R. An overview of membership function generation techniques for pattern recognition. Int. J. Approx. Reason. 1998, 19, 391-417. [CrossRef]

5. Medaglia, A.L.; Fang, S.C.; Nuttle, H.L.W.; Wilson, J.R. An efficient and flexible mechanism for constructing membership functions. Eur. J. Oper. Res. 2002, 139, 84-95. [CrossRef]

6. Mikhailov, L. Deriving priorities from fuzzy pairwise comparison judgements. Fuzzy Sets Syst. 2003, 134, 365-385. [CrossRef]

7. Appadoo, S.S. Possibilistic Fuzzy Net Present Value Model and Application. Math. Probl. Eng. 2014, $2014,865968$. [CrossRef]

8. Mikhailov, L.; Tsvetinov, P. Evaluation of services using a fuzzy analytic hierarchy process. Appl. Soft Comput. J. 2004, 5, 23-33. [CrossRef]

9. Deng, H.D.H. Multicriteria analysis with fuzzy pairwise comparison. In Proceedings of the FUZZ-IEEE'99. 1999 IEEE International Fuzzy Systems Conference Proceedings (Cat. No.99CH36315), Seoul, Korea, 22-25 August 1999; Volume 2, pp. 726-731. [CrossRef]

10. van Laarhoven, P.J.M.; Pedrycz, W. A fuzzy extension of Saaty's priority theory. Fuzzy Sets Syst. 1983, 11, $229-241$. [CrossRef]

11. Buckley, J.J. Fuzzy hierarchical analysis. Fuzzy Sets Syst. 1985, 17, 233-247. [CrossRef]

12. Chang, D.-Y. Applications of the extent analysis method on fuzzy AHP. Eur. J. Oper. Res. 1996, 95, 649-655. [CrossRef]

13. Enea, M.; Piazza, T. Project selection by constrained fuzzy AHP. Fuzzy Optim. Decis. Mak. 2004, 3, 39-62. [CrossRef]

14. Krejčí, J.; Pavlačka, O.; Talašová, J. A fuzzy extension of Analytic Hierarchy Process based on the constrained fuzzy arithmetic. Fuzzy Optim. Decis. Mak. 2017, 16, 89-110. [CrossRef]

15. Cakir, O.; Canbolat, M.S. A web-based decision support system for multi-criteria inventory classification using fuzzy AHP methodology. Expert Syst. Appl. 2008, 35, 1367-1378. [CrossRef]

16. Isaai, M.T.; Kanani, A.; Tootoonchi, M.; Afzali, H.R. Intelligent timetable evaluation using fuzzy AHP. Expert Syst. Appl. 2011, 38, 3718-3723. [CrossRef]

17. Buyukozkan, G.; Guleryuz, S. A new integrated intuitionistic fuzzy group decision making approach for product development partner selection. Comput. Ind. Eng. 2016, 102, 383-395. [CrossRef]

18. Zheng, G.; Zhu, N.; Tian, Z.; Chen, Y.; Sun, B. Application of a trapezoidal fuzzy AHP method for work safety evaluation and early warning rating of hot and humid environments. Saf. Sci. 2012, 50, 228-239. [CrossRef] 
19. Calabrese, A.; Costa, R.; Menichini, T. Using Fuzzy AHP to manage Intellectual Capital assets: An application to the ICT service industry. Expert Syst. Appl. 2013, 40, 3747-3755. [CrossRef]

20. Ishizaka, A.; Nguyen, N.H. Calibrated fuzzy AHP for current bank account selection. Expert Syst. Appl. 2013, 40, 3775-3783. [CrossRef]

21. Alavi, I. Fuzzy ahp method for plant species selection in mine reclamation plans: Case study sungun copper mine. Iran. J. Fuzzy Syst. 2014, 11, 23-38.

22. Somsuk, N.; Laosirihongthong, T. A fuzzy AHP to prioritize enabling factors for strategic management of university business incubators: Resource-based view. Technol. Forecast. Soc. Chang. 2014, 85, 198-210. [CrossRef]

23. Chan, H.K.; Wang, X.; Raffoni, A. An integrated approach for green design: Life-cycle, fuzzy AHP and environmental management accounting. Br. Account. Rev. 2014, 46, 344-360. [CrossRef]

24. Tan, R.R.; Aviso, K.B.; Huelgas, A.P.; Promentilla, M.A.B. Fuzzy AHP approach to selection problems in process engineering involving quantitative and qualitative aspects. Process Saf. Environ. Prot. 2014, 92, 467-475. [CrossRef]

25. Rezaei, J.; Fahim, P.B.M.; Tavasszy, L. Supplier selection in the airline retail industry using a funnel methodology: Conjunctive screening method and fuzzy AHP. Expert Syst. Appl. 2014, 41, 8165-8179. [CrossRef]

26. Song, Z.; Zhu, H.; Jia, G.; He, C. Comprehensive evaluation on self-ignition risks of coal stockpiles using fuzzy AHP approaches. J. Loss Prev. Process Ind. 2014, 32, 78-94. [CrossRef]

27. Dong, M.; Li, S.; Zhang, H. Approaches to group decision making with incomplete information based on power geometric operators and triangular fuzzy AHP. Expert Syst. Appl. 2015, 42, 7846-7857. [CrossRef]

28. Erdogan, M.; Kaya, I. An integrated multi-criteria decision-making methodology based on type-2 fuzzy sets for selection among energy alternatives in turkey. Iran. J. Fuzzy Syst. 2015, 12, 1-25. [CrossRef]

29. Mangla, S.K.; Kumar, P.; Barua, M.K. Risk analysis in green supply chain using fuzzy AHP approach: A case study. Resour. Conserv. Recycl. 2015, 104, 375-390. [CrossRef]

30. Mosadeghi, R.; Warnken, J.; Tomlinson, R.; Mirfenderesk, H. Comparison of Fuzzy-AHP and AHP in a spatial multi-criteria decision making model for urban land-use planning. Comput. Environ. Urban Syst. 2015, 49, 54-65. [CrossRef]

31. Lupo, T. A fuzzy framework to evaluate service quality in the healthcare industry: An empirical case of public hospital service evaluation in Sicily. Appl. Soft Comput. 2016, 40, 468-478. [CrossRef]

32. Tuljak-suban, D.; Bajec, P. The Influence of Defuzzification Methods to Decision Support Systems Based on Fuzzy AHP with Scattered Comparison Matrix: Application to 3PLP Selection as a Case Study. Int. J. Uncertain. Fuzziness Knowl. Based Syst. 2018, 26, 475-491. [CrossRef]

33. Akbar, M.A.; Shameem, M.; Mahmood, S.; Alsanad, A.; Gumaei, A. Prioritization Based Taxonomy of Cloud-based Outsource Software Development Challenges: Fuzzy AHP Analysis. Appl. Soft Comput. J. 2020, 95, 106557. [CrossRef]

34. Jung, H. A fuzzy AHP-GP approach for integrated production-planning considering manufacturing partners. Expert Syst. Appl. 2011, 38, 5833-5840. [CrossRef]

35. Shaw, K.; Shankar, R.; Yadav, S.S.; Thakur, L.S. Supplier selection using fuzzy AHP and fuzzy multi-objective linear programming for developing low carbon supply chain. Expert Syst. Appl. 2012, 39, 8182-8192. [CrossRef]

36. Abdullah, L.; Zulkifli, N. Integration of fuzzy AHP and interval type-2 fuzzy DEMATEL: An application to human resource management. Expert Syst. Appl. 2015, 42, 4397-4409. [CrossRef]

37. Vatansever, K.; Uluköy, M. Kurumsal Kaynak Planlaması Sistemlerinin Bulanık Ahp Ve Bulanık Moora Yöntemleriyle Seçimi: Üretim Sektöründe Bir Uygulama. Celal Bayar Üniversitesi Sos. Bilim. Derg. 2013, 11, 274-293.

38. Akkaya, G.; Turanoğlu, B.; Öztaş, S. An integrated fuzzy AHP and fuzzy MOORA approach to the problem of industrial engineering sector choosing. Expert Syst. Appl. 2015, 42, 9565-9573. [CrossRef]

39. Kutlu, A.C.; Ekmekçioğlu, M. Fuzzy failure modes and effects analysis by using fuzzy TOPSIS-based fuzzy AHP. Expert Syst. Appl. 2012, 39, 61-67. [CrossRef]

40. Büyüközkan, G.; Çifçi, G. A combined fuzzy AHP and fuzzy TOPSIS based strategic analysis of electronic service quality in healthcare industry. Expert Syst. Appl. 2012, 39, 2341-2354. [CrossRef]

41. Taylan, O.; Bafail, A.O.; Abdulaal, R.M.S.; Kabli, M.R. Construction projects selection and risk assessment by fuzzy AHP and fuzzy TOPSIS methodologies. Appl. Soft Comput. J. 2014, 17, 105-116. [CrossRef] 
42. Patil, S.K.; Kant, R. A fuzzy AHP-TOPSIS framework for ranking the solutions of Knowledge Management adoption in Supply Chain to overcome its barriers. Expert Syst. Appl. 2014, 41, 679-693. [CrossRef]

43. Sun, L.; Ma, J.; Zhang, Y.; Dong, H.; Hussain, F.K. Cloud-FuSeR: Fuzzy ontology and MCDM based cloud service selection. Future Gener. Comput. Syst. 2016, 57, 42-55. [CrossRef]

44. Ar, I.M.; Erol, I.; Peker, I.; Ozdemir, A.I.; Medeni, T.D.; Medeni, I.T. Evaluating the feasibility of blockchain in logistics operations: A decision framework. Expert Syst. Appl. 2020, 158, 113543. [CrossRef]

45. Yalcin, N.; Bayrakdaroglu, A.; Kahraman, C. Application of fuzzy multi-criteria decision making methods for financial performance evaluation of Turkish manufacturing industries. Expert Syst. Appl. 2012, 39, 350-364. [CrossRef]

46. Chang, S.-C.; Tsai, P.-H.; Chang, S.-C. A hybrid fuzzy model for selecting and evaluating the e-book business model: A case study on Taiwan e-book firms. Appl. Soft Comput. 2015, 34, 194-204. [CrossRef]

47. Li, N.; Zhao, H. Performance evaluation of eco-industrial thermal power plants by using fuzzy GRA-VIKOR and combination weighting techniques. J. Clean. Prod. 2016, 135, 169-183. [CrossRef]

48. Mandic, K.; Delibasic, B.; Knezevic, S.; Benkovic, S. Analysis of the financial parameters of Serbian banks through the application of the fuzzy AHP and TOPSIS methods. Econ. Model. 2014, 43, 30-37. [CrossRef]

49. Li, Y.; Liu, X.; Chen, Y. Supplier selection using axiomatic fuzzy set and TOPSIS methodology in supply chain management. Fuzzy Optim. Decis. Mak. 2012, 11, 147-176. [CrossRef]

50. Kaya, Ö.; Alemdar, K.D.; Çodur, M.Y. A novel two stage approach for electric taxis charging station site selection. Sustain. Cities Soc. 2020, 62, 102396. [CrossRef]

51. Chen, J.-F.; Hsieh, H.-N.; Do, Q.H. Evaluating teaching performance based on fuzzy AHP and comprehensive evaluation approach. Appl. Soft Comput. 2015, 28, 100-108. [CrossRef]

52. Javanbarg, M.B.; Scawthorn, C.; Kiyono, J.; Shahbodaghkhan, B. Fuzzy AHP-based multicriteria decision making systems using particle swarm optimization. Expert Syst. Appl. 2012, 39, 960-966. [CrossRef]

53. Che, Z.H.; Wang, H.S.; Chuang, C.L. A fuzzy AHP and DEA approach for making bank loan decisions for small and medium enterprises in Taiwan. Expert Syst. Appl. 2010, 37, 7189-7199. [CrossRef]

54. Krejčí, J. Additively reciprocal fuzzy pairwise comparison matrices and multiplicative fuzzy priorities. Soft Comput. 2017, 21, 3177-3192. [CrossRef]

55. Xu, Z.; Liao, H. Intuitionistic fuzzy analytic hierarchy process. IEEE Trans. Fuzzy Syst. 2014, $22,749-761$. [CrossRef]

56. Mikhailov, L. A fuzzy programming method for deriving priorities in the analytic hierarchy process. J. Oper. Res. Soc. 2000, 51, 341-349. [CrossRef]

57. Appadoo, S.S. Pricing Financial Derivatives with Fuzzy Algebraic Models: A Theoretical and Computational Approach. Ph.D. Thesis, University of Manitoba, Winnipreg, MB, Canada, 2006.

Publisher's Note: MDPI stays neutral with regard to jurisdictional claims in published maps and institutional affiliations.

(C) 2020 by the authors. Licensee MDPI, Basel, Switzerland. This article is an open access article distributed under the terms and conditions of the Creative Commons Attribution (CC BY) license (http://creativecommons.org/licenses/by/4.0/). 